\title{
Stauffer syndrome, clinical implications and knowledge gaps, does size matter? Case report
}

\author{
Julian Chavarriaga * D N Nayib Fakih, Juan Cataño, Catalina Villaquiran, Santiago Rodriguez and German Patino
}

\begin{abstract}
Background: Stauffer Syndrome (SS) is a paraneoplastic disorder associated with renal cell carcinoma (RCC). First described by Herbert Maurice Stauffer in 1961, it is characterized by hepatic dysfunction in the absence of metastasis, and elevated alkaline phosphatase, aminotransferases and prolonged prothrombin time. Initial reports did not include jaundice as an inclusion criterion. We aim to report the rare SS jaundice variant in a patient with a small renal mass and review the literature to determine if the size of the renal mass could influence the development of the SS.

Case presentation: The aim of this article is to present the case of a 53-year-old male with Stauffer syndrome jaundice variant secondary to a $2.5 \mathrm{~cm}$ renal mass, treated with laparoscopic radical nephrectomy with complete resolution of the syndrome.

Conclusions: This syndrome is yet to be fully understood, and as far as the evidence shows, size does not matter. This entity should always be in mind when encountered with a patient with liver dysfunction and jaundice with a suspicion or confirmed diagnosis of a renal mass. To date, and to our knowledge, there have been eleven reported cases of paraneoplastic cholestatic jaundice syndrome including the current case. Six cases presented in patients with small renal mases $(<4 \mathrm{~cm})$, curiously there were not a laterality tendency.
\end{abstract}

Keywords: Carcinomas, renal cell, Paraneoplastic syndrome, Liver dysfunctions, Jaundice, Cholestatic, Case report

\section{Background}

Renal cell carcinoma (RCC) accounts for $2 \%$ of all cancers. The classic diagnostic triad of palpable abdominal mass, hematuria and right flank pain is only present in $10 \%$ of patients [1]. It has been related to many paraneoplastic syndromes, ranging between neuromyopathy, polycythemia, malignant hypercalcemia, anemia, and liver dysfunction [2]. Stauffer syndrome (SS) is one of the most characteristic paraneoplastic syndromes associated with RCC. First described in 1961 by Herbert Stauffer, the five originally reported cases presented: hypernephroma

\footnotetext{
* Correspondence: chavarriagaj@javeriana.edu.co

Division of Urologic Oncology, Pontificia Universidad Javeriana, Hospital Universitario San Ignacio, Carrera 7 No. 40 - 62, Bogotá, Colombia 11011
}

(nowadays RCC), hypoalbuminemia, hypergammaglobulinemia, high alkaline phosphatase (ALP), prolonged prothrombin time (PT) with normalization of liver function tests (LFTs) after tumor resection [3]. The incidence in patients with RCC varies between 3 and 6\% $[4,5]$. Development of SS has been associated with bad prognosis [4, 5], a few case reports of SS include jaundice as a diagnostic variable [6]. Most case reports have usually shown very large renal masses [7].

The aim of this article is to present the rare case of a 53-year-old male with a small renal mass (SRM), who developed SS with jaundice and liver dysfunction, and underwent laparoscopic radical nephrectomy with complete resolution of the syndrome features after treatment of the primary lesion.

(C) The Author(s). 2020 Open Access This article is licensed under a Creative Commons Attribution 4.0 International License, which permits use, sharing, adaptation, distribution and reproduction in any medium or format, as long as you give appropriate credit to the original author(s) and the source, provide a link to the Creative Commons licence, and indicate if changes were made. The images or other third party material in this article are included in the article's Creative Commons licence, unless indicated otherwise in a credit line to the material. If material is not included in the article's Creative Commons licence and your intended use is not permitted by statutory regulation or exceeds the permitted use, you will need to obtain permission directly from the copyright holder. To view a copy of this licence, visit http://creativecommons.org/licenses/by/4.0/ The Creative Commons Public Domain Dedication waiver (http://creativecommons.org/publicdomain/zero/1.0/) applies to the data made available in this article, unless otherwise stated in a credit line to the data. 


\section{Case presentation}

A 53-year-old male presented to the emergency department (ER) with right upper quadrant abdominal pain, jaundice, pruritus, choluria and acholia. His complete blood count $(\mathrm{CBC})$ was normal. Abnormal LFTs: total bilirubin of $19.91 \mathrm{mg} / \mathrm{dl}$, Aspartate Transaminase (AST) $418 \mathrm{U} / \mathrm{L}$, Alanine transaminase (ALT) $695 \mathrm{U} / \mathrm{L}$. Lactate Dehydrogenase (LDH), albumin, prothrombin and thromboplastin times were normal, INR was 1. HIV, hepatitis B, C, Epstein-Barr virus (EBV) antibodies, and peripheral blood smear were within normal ranges. Autoimmune disorders comprehensive panel was normal. Past medical history was non remarkable and acetaminophen toxicity was ruled out at ER admission.

Radiological work up, with computerized tomography (CT) showed a $24 \times 29 \times 33 \mathrm{~mm}$ renal mass, at the interpolar region of the right kidney with a RENAL nephrometry score of 9 (moderate complexity), with hepatosplenomegaly and without signs of choledocholithiasis, pancreatic masses or metastasis. (Figure 1) Chest CT was unremarkable. The magnetic resonance imaging (MRI) cholangiopancreatography and portal doppler ultrasound ruled out any other structural disease.

As the bilirubin levels kept increasing and after ruling out all differential diagnosis, Gastroenterology and Hepatology got consulted and they suggested a jaundice variant of the Stauffer paraneoplastic syndrome, patient was scheduled for urgent laparoscopic radical nephrectomy instead of a nephron-sparing approach considering that liver dysfunction could imply a higher surgical bleeding risk. Surgery was performed without complications, total bleeding was $100 \mathrm{ml}$. Postoperative course was uneventful, and in postoperative day 3 , upon discharge, total bilirubin was $3.31 \mathrm{mg} / \mathrm{dL}$, alkaline
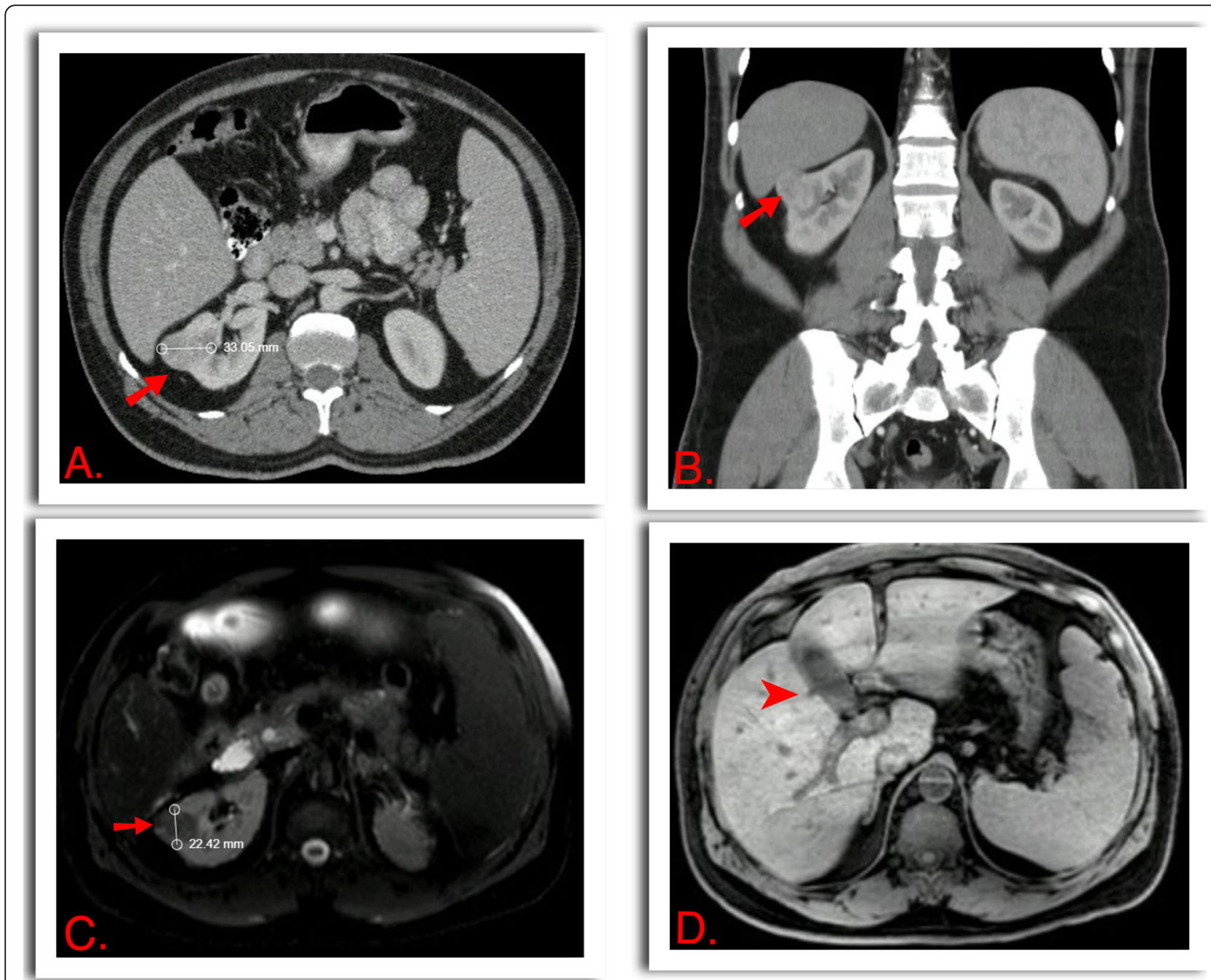

Fig. 1 a and b. Computed tomography showed a solid exophytic mass (arrow) measuring $24 \times 29 \times 33$ mm in the right kidney, RENAL score 9x. c. Contrast enhanced MRI, T2W, showed a $22 \mathrm{~mm}$ renal mass in the long axis, which enhanced with IV contrast. d. Hepato-Splenomegaly characteristic of the Stauffer syndrome, Gallbladder and hepatic biliary ducts were not dilated (Arrow head) 
phosphatase 181 U/L, AST 93 U/L, ALT 231 U/L. Surgical pathology revealed a pT1a, $2.5 \mathrm{~cm}$ clear cell carcinoma, WHO/ISUP nucleolar grade 2. (Figure 2) At 6 months follow up improvement of LFTs has remained normalized and hepatosplenomegaly has resolved, confirmed with US.

\section{Discussion and conclusions}

Stauffer syndrome is an uncommon paraneoplastic syndrome $[4,5]$. It is usually associated with RCC, but it can present along with other types of malignancies such as soft-tissue sarcomas, prostate cancer and malignant lymphoproliferative diseases $[3,5]$. Stauffer syndrome can be divided into a classic presentation and jaundice variant. The latter is characterized by high alkaline phosphatase, thrombocytosis, elevated erythrocyte sedimentation rate, hyperbilirubinemia, hepatosplenomegaly, in some cases, abnormal coagulation profile and hypoalbuminemia, jaundice, choluria, pruritus are clinical features of this syndrome $[3,5,8]$. Our case corresponds to the aforementioned jaundice variant.

Interleukin-6 (IL-6) has been proposed to play a major role in the pathophysiology of this syndrome $[3,5,9]$. Bhangoo, et al suggested that cholestasis could be secondary to pro-inflammatory activity of IL- 6 cytokine which causes elevation of C-reactive protein, haptoglobin and inhibits the hepatobiliary transporter gene expression which impairs biliary outflow $[9,10]$. Patients with detectable serum IL-6 had significantly higher hepatic compromise with elevated LFTs [9]. Karakolios et al. conducted a study treating patients with SS with anti-IL6 monoclonal antibodies and found that it reversed most of the biochemical abnormalities of these patients [11]. Despite these findings, the precise mechanism of the disease remains poorly understood, the association of this condition with IL-6 remains speculative and other humoral mediators have also been proposed such as an increase in lysosomal enzyme activity in liver cells of patients with RCC, which has effects on the liver and hematopoietic system [5] and the lack of humoral secretion inhibition by suramin [12].

Autopsy findings have revealed hepatic sinusoidal dilation without congestion of the central hepatic vein or hepatocellular necrosis [3]. Interestingly in more recent years, immune checkpoint inhibitors such as Programmed death ligand 1/Programmed cell death protein1 (PD-L1/PD-1) have been approved as treatment for metastatic RCC. These medications, with immunemediated mechanisms of action, may explain their efficacy and correlation to the pathophysiology of Stauffer Syndrome $[3,5,13]$. It has been reported that IL-6/JAK1 pathway promotes cancer immune evasion through phosphorylation of PD-L1 (Tyr112) [13].

A rare variant of the syndrome presents initially with jaundice, as in this case. It was first reported by Dourakis, et al in 1997 [8]. Two patients presented to the

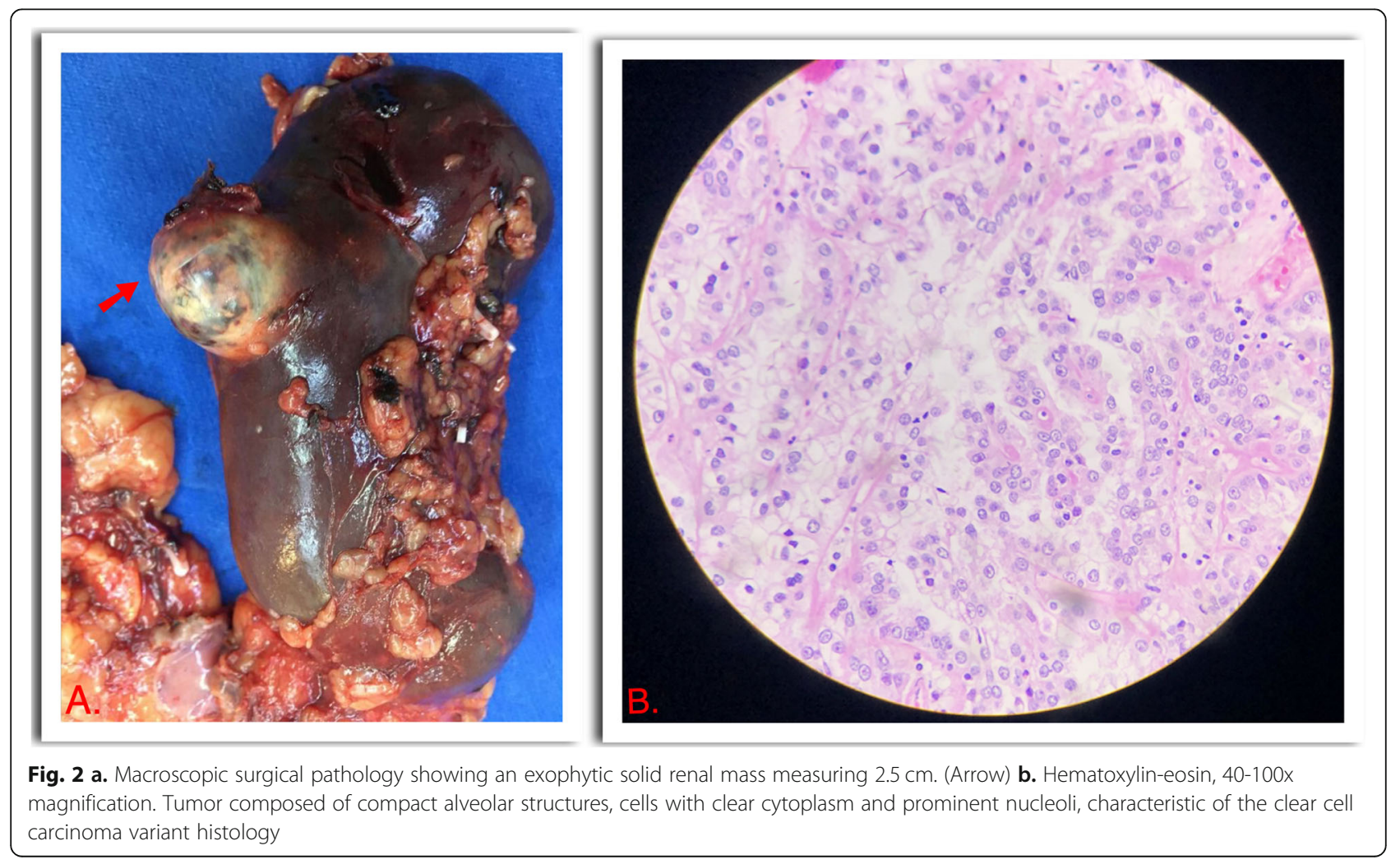


Table 1 Clinical characteristics of patients with Stauffer syndrome variant with cholestatic jaundice due to RCC

\begin{tabular}{llllllllllll}
\hline Clinical studies & $n$ & Age (Years) & Laterality & Tumor size (cm) & AST & ALT & ALP & INR & Bilirrubin & Treatment & Histology \\
\hline Chavarriaga et al. (2020) & $n=1$ & 53 & Right & 3 & 418 & 695 & 337 & 1 & 19.91 & RLN & RCCcc \\
Dewana et al. (2019) [7] & $n=1$ & 32 & Right & 19 & 74 & 30 & 253 & 3.2 & 9.25 & ORN & SCS \\
Gremida et al. (2017) [14] & $n=1$ & 55 & Left & 2.5 & 29 & 34 & 327 & 1.6 & 20.9 & RLN & RCCcc \\
Puga et al. (2015) [15] & $n=1$ & 69 & Right & 6.2 & 57 & 50 & 367 & 1.2 & 22.9 & RLNU & pRCC \\
Fernandez et al. (2012) [16] & $n=1$ & 70 & Left & NR & 672 & 397 & 222 & 2.04 & 10.3 & RLN & NR \\
Tomadini et al. (2010) [17] & $n=1$ & 51 & Left & 4 & N & N & 7860 & N & 13.6 & ORN & RCCcc \\
Mazokopakis et al. (2007) [18] & $n=1$ & 50 & Left & $>7$ & 227 & 260 & 187 & 2.9 & 2.1 & ORN & RCC \\
Morla et al. (2006) [6] & $n=1$ & 39 & Left & 4 & 146 & 24 & 219 & 1.12 & 16.8 & ORN & RCCcc \\
Giannakos et al. (2005) [19] & $n=1$ & 73 & Right & 3 & 240 & 123 & 287 & NR & 38.1 & ORN & RCCcc \\
Dourakis et al. (1997) [8] & $n=1$ & 65 & Right & 2.5 & 158 & 426 & 163 & NR & 6.2 & ORN & RCCcc \\
Dourakis et al. (1997) [8] & $n=1$ & 48 & Right & $>10$ & 132 & 334 & 193 & NR & 2.8 & ORN & RCCcc \\
\hline
\end{tabular}

RCC Renal cell carcinoma, RCCCC Clear Cell, pRCC Papillary, SCS Synovial Cell Sarcoma, ALP Alkaline phospatase, ALT alanine aminotransferase, AST aspartate transaminase, RLN Radical laparoscopic Npehrectomy, ORN Open Radical Nephrectomy, NR Not reported, INR international normalized ratio of prothrombin time of blood coagulation, $N$ Normal

emergency department complaining of jaundice, and one of them had also right upper quadrant pain. Both patients had right renal masses that once were removed, symptoms improved quite rapidly. In 2005 Giannakos, et al also reported a 73-year-old male with jaundice, pruritus, choluria and hepatomegaly. A $3 \mathrm{~cm}$ right lower pole renal mass was seen in a CT scan, and once removed, symptoms resolved as well.

To date, and to our knowledge, there have been eleven reported cases of paraneoplastic cholestatic jaundice syndrome in the literature including the current case [5-8]. Clinical characteristics and laboratory and imaging work up is shown on Table 1 [5]. Six cases presented in patients with SRM $(<4 \mathrm{~cm})$, curiously there were not a laterality tendency, 6 RCCs were located in the right kidney and 5 in the left and most (8) were clear cell histology [5-8].

This syndrome is yet to be fully understood, and as far as the evidence shows, size does not matter. This entity should always be in mind when encountered with a patient with liver dysfunction and jaundice with a suspicion or confirmed diagnosis of a renal mass. Efforts should be made to clarify the precise pathophysiology of this syndrome, molecular studies in patients suffering from SS and serum tests looking for pro-inflammatory cytokines should be taken into account when diagnosing and treating this rare syndrome, all these to finally define targeted therapy while the patient awaits the surgical treatment given the considerable risk of bleeding in a patient with liver dysfunction.

\section{Abbreviations}

SS: Stauffer Syndrome; RCC: Renal cell carcinoma; ALP: Alkaline phosphatase; PT: Prothrombin time; LFTs: Liver function tests; SRM: Small renal mass; CBC: Complete blood count; ALT: Alanine transaminase; AST: Aspartate Transaminase; LDH: Lactate Dehydrogenase; CT: Computerized tomography; MRI: Magnetic resonance imaging; IL-6: Interleukin-6; PD-L1: Programmed death-ligand 1; PD-1: Programmed cell death protein 1
Acknowledgements

We Acknowledge Nicolas Fernandez M.D. PhD for his significant contribution in laparoscopic surgery teaching skills.

\section{Authors' contributions}

NF: Protocol/Project development, Data collection, manuscript writing, Figures and tables design. JCH: Protocol/Project development, Data collection, manuscript writing, Figures and tables design. JC: Protocol/Project development, manuscript writing, data analysis. CV: Data collection, manuscript writing, data analysis. SR: Data collection, data analysis. GP: Protocol/Project development, manuscript writing. All authors read and approved the final manuscript.

\section{Funding}

The authors have no funding sources to declare.

Availability of data and materials

The datasets used and/or analysed during the current study are available from the corresponding author on reasonable request.

\section{Ethics approval and consent to participate}

The patient in this manuscript has given his full written and verbal consent to publish photos and details of the case. The case report was approved by the ethics committee on human research of the Pontificia Universidad Javeriana, IRB \#20200411-185.

\section{Consent for publication}

The patient in this manuscript has given his full written and verbal consent to publish anonymous photos and clinical and laboratory details of the case.

\section{Competing interests}

The authors declare that they have no competing interests.

Received: 8 May 2020 Accepted: 8 July 2020

Published online: 20 July 2020

References

1. Stauffer HM. Nephrogenic hepatosplenomegaly. Gastroenterology. 1961;40: 694-6.

2. Gold PJ, Fefer A, Thompson JA. Paraneoplastic manifestations of renal cell carcinoma. Semin Urol Oncol. 1996;14(4):216-22.

3. Fontes-Sousa M, Magalhães H, da Silva FC, Maurício MJ. Stauffer's syndrome: a comprehensive review and proposed updated diagnostic criteria. Urol Oncol Semin Orig Investig. 2018:36(7):321-6. https://doi.org/10.1016/j. urolonc.2018.01.019. 
4. Boxer RJ, Waisman J, Lieber MM, Mampaso FM, Skinner DG. Non-metastatic hepatic dysfunction associated with renal carcinoma. J Urol. 1978;119(4): 468-71. https://doi.org/10.1016/S0022-5347(17)57519-9.

5. Sharma N, Darr U, Darr A, Sood G. Stauffer Syndrome: a comprehensive review of the icteric variant of the syndrome. Cureus. 2019;11(10):e6032. https://doi.org/10.7759/cureus.6032.

6. Morla D, Alazemi S, Lichtstein D. Stauffer's syndrome variant with cholestatic jaundice: a case report. J Gen Intern Med. 2006;21(7):11-3. https://doi.org/ 10.1111/j.1525-1497.2006.00448.x.

7. Dewana SK, Parmar KM, Sharma G, Bansal A, Panwar P, Mavuduru RS. Paraneoplastic hepatic dysfunction with jaundice in a case of primary renal synovial sarcoma: a very rare scenario. Urol Case Rep. 2019;24(December 2018):100841. https://doi.org/10.1016/.jeucr.2019.100841.

8. Dourakis SP, Sinani C, Deutsch M, Dimitriaclou E, Hadziyannis SJ. Cholestatic jaundice as a paraneoplastic manifestation of renal cell carcinoma. Eur J Gastroenterol Hepatol. 1997;9(3):311-4. https://doi.org/10.1097/00042737199703000-00018.

9. Blay JY, Rossi JF, Wijdenes J, et al. Role of interleukin-6 in the paraneoplastic inflammatory syndrome associated with renal-cell carcinoma. Int I Cancer. 1997;72(3):424-30. https://doi.org/10.1002/(SICI)1097-0215(19970729)72:3< 424::AID-IJC9>3.0.CO;2-R.

10. Bhangoo M, Cheng B, Botta G, Thorson P, Kosty M. Reversible intrahepatic cholestasis in metastatic prostate cancer: an uncommon paraneoplastic syndrome. Mol Clin Oncol. 2018;8:609-12. https://doi.org/10.3892/mco.2018. 1564.

11. Karakolios A, Kasapis C, Kallinikidis T, Kalpidis P, Grigoriadis N. Cholestatic jaundice as a paraneoplastic manifestation of prostate adenocarcinoma. Clin Gastroenterol Hepatol. 2003;1 (6):480-3. https://doi.org/10.1016/S15423565(03)00227-1.

12. Chang SY, Yu DS, Sherwood ER, Kozlowski JM, Lee C. Inhibitory effects of suramin on a human renal cell carcinoma line, causing nephrogenic hepatic dysfunction. J Urol. 1992;147(4):1147-50. https://doi.org/10.1016/S00225347(17)37505-5.

13. Chan L, Wang S, Hung M, et al. IL-6 / JAK1 pathway drives PD-L1 Y112 phosphorylation to promote cancer immune evasion find the latest version: IL-6 / JAK1 pathway drives PD-L1 Y112 phosphorylation to promote cancer immune evasion. J Clin Invest. 2019:129(8):3324-38.

14. Gremida A, Al-Taee A, Alcorn J, et al. Hepatic Dysfunction in Renal Cell Carcinoma: Not What You Think?. Dig Dis Sci. 2017;62:2298-2302. https:// doi.org/10.1007/s10620-017-4706-8.

15. Puga M, Gonzalez-Ballina E, Rivas-Moral L. Stauffer's syndrome variant as an unusual case of painless jaundice. Clin Gastroenterol Hepatol. 2015;13(9): A25-A26.

16. Fernández AB, de Ávila AS. Prothrombin complex concentrate (Octaplex) for postsurgical bleeding control in a Stauffer's syndrome. Ann Hematol. 2012; 91(8):1325

17. Tomadoni A, Garcia C, Marquez M, Ayala JC, Prado F. Stauffer's Syndrome with jaundice, a paraneoplastic manifestation of renal cell carcinoma: A case report. Arch Esp Urol. 2010;63(2):54.

18. Mazokopakis EE, Papadakis JA, Kofteridis DP. Unusual causes of intrahepatic cholestatic liver disease. World J Gastroenterol. 2007;13(12):1879.

19. Giannakos G, Papanicolaou X, Trafalis D, Michaelidis I, Margaritis G, Christofilakis C. Stauffer's syndrome variant associated with renal cel carcinoma. Int J Urol. 2005;12(8):757-759.

\section{Publisher's Note}

Springer Nature remains neutral with regard to jurisdictional claims in published maps and institutional affiliations.

Ready to submit your research? Choose BMC and benefit from:

- fast, convenient online submission

- thorough peer review by experienced researchers in your field

- rapid publication on acceptance

- support for research data, including large and complex data types

- gold Open Access which fosters wider collaboration and increased citations

- maximum visibility for your research: over $100 \mathrm{M}$ website views per year

At BMC, research is always in progress.

Learn more biomedcentral.com/submissions 